Article

\title{
The Antileishmanial Potential of C-3 Functionalized Isobenzofuranones against Leishmania (Leishmania) Infantum Chagasi
}

\author{
Wagner Luiz Pereira ${ }^{1,+}$, Raphael de Souza Vasconcellos $2,3,+$, Christiane Mariotini-Moura ${ }^{2,3}$, \\ Rodrigo Saar Gomes ${ }^{4}$, Rafaela de Cássia Firmino ${ }^{2,3}$, Adalberto Manoel da Silva ${ }^{1}$, \\ Abelardo Silva Júnior ${ }^{5}$, Gustavo Costa Bressan ${ }^{6}$, Márcia Rogéria Almeida ${ }^{6}$, \\ Luís Carlos Crocco Afonso ${ }^{4}$, Róbson Ricardo Teixeira ${ }^{1, *,+}$ and Juliana Lopes Rangel Fietto ${ }^{3,6, *,+}$ \\ Received: 5 November 2015 ; Accepted: 8 December 2015 ; Published: 14 December 2015 \\ Academic Editor: Derek J. McPhee \\ 1 Departamento de Química, Universidade Federal de Viçosa, Av. P.H. Rolfs, S/N, Viçosa, MG 36.570-900, \\ Brazil; wagner.pereira@ufv.br (W.L.P.); adalbert31@hotmail.com (A.M.S.) \\ 2 Departamento de Biologia Geral, Universidade Federal de Viçosa, Av. P.H. Rolfs, S/N, Viçosa, \\ MG 36.570-900, Brazil; raphael.biomed@gmail.com (R.S.V.); chrismariotini@yahoo.com.br (C.M.-M.); \\ rafaelacfirmino@gmail.com (R.C.F.) \\ 3 Instituto Nacional de Biotecnologia Estrutural e Química Medicinal em Doenças Infecciosas (INBEQMeDi), \\ Instituto de Física de São Carlos, Av. Trabalhador São Carlense, 400, Caixa Postal 369, São Carlos, \\ SP 13.560-970, Brazil \\ 4 Departamento de Ciências Biológicas, Instituto de Ciências Exatas e Biológicas-ICEB/NUPEB, \\ Campus do Morro do Cruzeiro, Universidade Federal de Ouro Preto, Ouro Preto, MG 35.400-000, Brazil; \\ rodrigosaar@nupeb.ufop.br (R.S.G.); afonso@nupeb.ufop.br (L.C.C.A.) \\ 5 Departamento de Veterinária, Universidade Federal de Viçosa, Av. P.H. Rolfs, S/N, Viçosa, MG 36.570-900, \\ Brazil; aberlardo.junior@ufv.br \\ 6 Departamento de Bioquímica e Biologia Molecular, Av. P.H. Rolfs, S/N, Viçosa, MG 36.570-900, Brazil; \\ gustavo.bressan@ufv.br (G.C.B.); marcia@ufv.br (M.R.A.) \\ * Correspondence: robsonr.teixeira@ufv.br (R.R.T.); jufietto@ufv.br (J.L.R.F.); Tel.: +55-31-3899-3209 (R.R.T.); \\ +55-31-3899-2374 (J.L.R.F.); Fax: +55-31-3899-2373 (J.L.R.F.) \\ + These authors contributed equally to this work.
}

Abstract: Leishmaniases are diseases caused by protozoan parasites of the genus Leishmania. Clinically, leishmaniases range from cutaneous to visceral forms, with estimated global incidences of 1.2 and 0.4 million cases per year, respectively. The treatment of these diseases relies on multiple parenteral injections with pentavalent antimonials or amphotericin B. However, these pharmaceuticals are either too toxic or expensive for routine use in developing countries. These facts call for safer, cheaper, and more effective new antileishmanial drugs. In this investigation, we describe the results of the assessment of the activities of a series of isobenzofuran-1(3H)-ones (phtalides) against Leishmania (Leishmania) infantum chagasi, which is the main causative agent of visceral leishmaniasis in the New World. The compounds were tested at concentrations of 100, 75, 50, 25 and $6.25 \mu \mathrm{M}$ over 24,48 , and $72 \mathrm{~h}$. After $48 \mathrm{~h}$ of treatment at the $100 \mu \mathrm{M}$ concentration, compounds 7 and 8 decreased parasite viability to $4 \%$ and $6 \%$, respectively. The concentration that gives half-maximal responses $\left(\mathrm{LC}_{50}\right)$ for the antileishmanial activities of compounds 7 and 8 against promastigotes after $24 \mathrm{~h}$ were 60.48 and $65.93 \mu \mathrm{M}$, respectively. Additionally, compounds 7 and 8 significantly reduced parasite infection in macrophages.

Keywords: Leishmania (L.) infantum chagasi; visceral leishmaniasis; isobenzofuranones; phthalides; in vitro leishmanicidal activity 


\section{Introduction}

The leishmaniases are parasitic diseases that are caused by protozoa of the genus Leishmania. These parasites belong to the order Kinetoplastida and family Trypanosomatidae, which includes species of obligatory intracellular protozoan parasites. Common hosts include rodents, canines and primates, including humans [1,2]. Leishmania infections can present with different clinical manifestations depending on the parasite species and the host-parasite relationship. Visceral leishmaniasis (VL) is a progressive and frequently fatal disease caused by Leishmania (Leishmania) infantum (synonymous with Leishmania (Leishmania) infantum chagasi) [3]. VL is one of the most neglected diseases in the world and affects millions of people worldwide [4]. Approximately 500,000 new cases occur annually, and $90 \%$ of all VL cases occurring in India, Bangladesh, Sudan, South Sudan, Ethiopia and Brazil [4].

Currently, several investigations are being conducted to search for alternative treatments for leishmaniases [5] because of the small number of available drugs and the development of resistance or decreased sensitivity of parasite strains to existing treatments that are utilized for human therapy [5]. These studies have sought new methods and targets for diagnosis, new vaccine candidates and new rationally designed drugs that can be applied not only in humans, but also in dogs because canines are considered the major reservoirs of several species of Leishmania in the home environment and outdoors [6,7].

Historically, chemotherapy for leishmaniases has relied on the use of pentavalent antimonial drugs, such as $\mathrm{N}$-methylglucamine antimoniate, which is one of the most widely used drugs [8]. However, the use of this drug has limited clinical potential due to the occurrence of serious side effects and high incidence of disease recurrence [9]. Pentamidine is another antileishmanial agent, but it is inadequate as a first-line treatment because of its high toxicity [10]. Amphotericin B has been used as a second-choice drug in the treatment of leishmaniasis since the 1960s, but the rate of resistance against this drug is high [10]. Two other examples of antileishmanial compounds are miltelfosine and paromomocyn. The major limitation of miltefosine is teratogenicity and this precludes its use in women of child-bearing age [11,12]. The most common side effect associated with paromomycin is the ototoxicity, as well as liver function problems. In patients treated with the ointment formulation skin rashes, local pruritus and burs have been the most common side effects encountered [13] Additionally, the drugs that are available for leishmaniasis chemotherapy are, in general, expensive. Another alternative is combination therapy, which has been used to decrease the duration and price of treatment and parasite resistance [14]. The aforementioned problems illustrate a pressing need to develop new antileishmanial drugs.

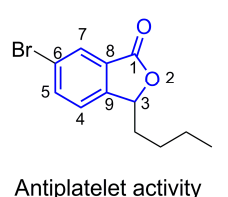

Antiplatelet activity

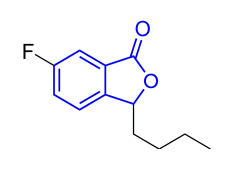

Inhibitor of glutamateinduced cytotoxicity

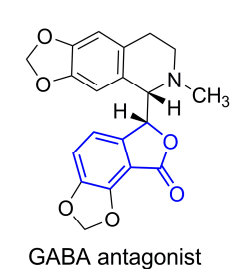

GABA antagonist
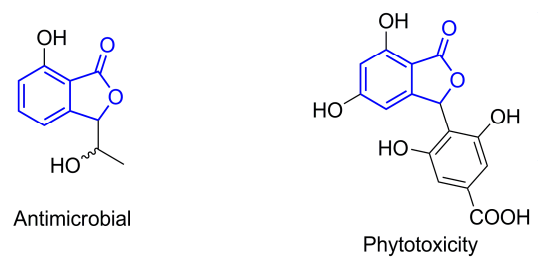

Figure 1. Example isobenzofuran-1(3H)-ones and their biological activities.

Compounds containing a benzene ring fused to a $\gamma$-lactone ring are termed isobenzofuran$1(3 H)$-ones (also known as phthalides). This unit is present in the structure of several natural products $[15,16]$. In particular, isobenzofuran- $1(3 H)$-ones functionalized at the C-3 position stand 
out for their biological activities, which include antiplatelet [17], GABA receptor antagonist [18], glutamate-induced cytotoxicity inhibitor [19], phytotoxicity [20], cytotoxicity [21,22] and antimicrobial activity [23]. Examples of isobenzofuranones and their associated bioactivities are shown in Figure 1, where the isobenzofuran-1(3H)-one unit is highlighted in blue.

Considering their various biological activities and our research interest in isobenzofuran-1(3H)ones [22,24], we herein describe the results of our investigation of the antileishmanial activities of C-3 functionalized isobenzofuranones on Leishmania (Leishmania) infantum chagasi.

\section{Results and Discussion}

It is well known that amphotericin B, which is used for the treatment of visceral leishmaniasis, is an effective antibiotic that also possesses antifungal activity [10]. Because previous studies have demonstrated that isobenzofuranones display antifungal activities $[25,26]$, we hypothesized that isobenzofuranones 2-11 (Scheme 1) would also exhibit antileishmanial activities.

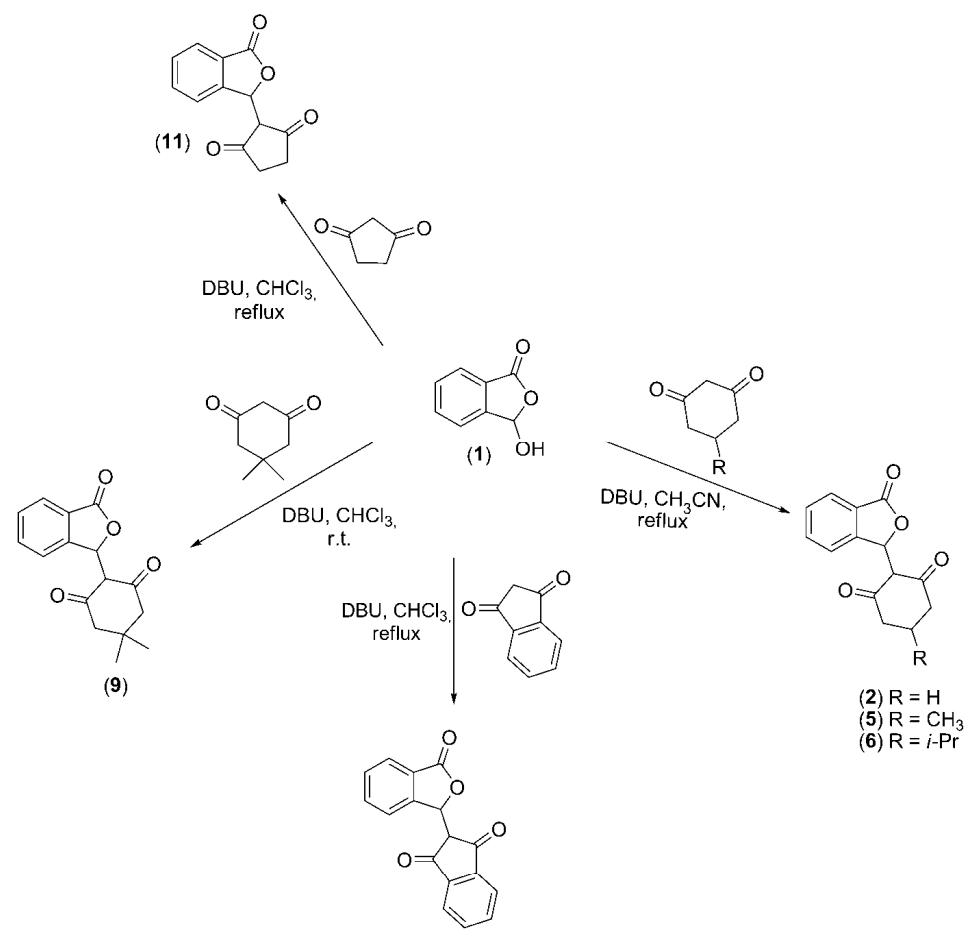

(10)

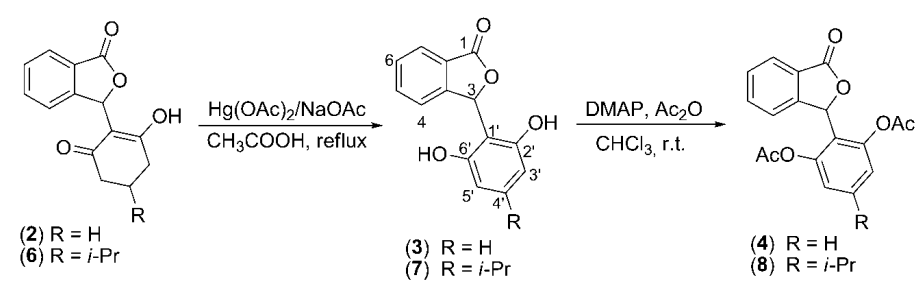

Scheme 1. Syntheses of isobenzofuranones 2-11.

Thus, we evaluated the antileishmanial activities of isobenzofuranones $\mathbf{2 - 5}$ and 7-11 (Scheme 1) against the pathogenic agent of visceral leishmaniasis Leishmania (L.) infantum chagasi (syn. Leishmania infantum). Because of limited amount of compound $\mathbf{6}$ available during the progress of the biological assays, this compound was not evaluated. The first approach involved evaluations of the direct actions of these compounds on the promastigote form of the parasite. 
We observed that all of the compounds were toxic to the parasite (Figure 2). After $24 \mathrm{~h}$ of treatment, the $100 \mu \mathrm{M}$ concentrations of compounds 7 and 8 significantly reduced parasite viability by over $50 \%$ (Figure 2A). After 48 and $72 \mathrm{~h}$, all of the isobenzofuranones were effective in decreasing parasite viability (Figure 2B,C). Additionally, 100\% parasite death was observed after $72 \mathrm{~h}$ of treatment with compounds 7 and 8 (Figure $2 \mathrm{C}$ ). Table 1 illustrates the $\mathrm{LC}_{50}$ antileishmanial activity values of compounds $\mathbf{2}-\mathbf{5}$ and $\mathbf{7 - 1 1}$ against the promastigote form of L. (L.) infantum (syn. L. chagasi). The most active compounds, i.e., 7 and 8 , exhibited $\mathrm{LC}_{50}$ values between $60.48-59.75$ and $65.93-58.46 \mu \mathrm{M}$, respectively.

Thus, the greatest antileishmanial efficacies against the promastigotes were observed for isobenzofuranones $\mathbf{7}$ and 8; importantly, these compounds share the common feature of an aromatic ring that is directly attached at the $\mathrm{C}-3$ position of the isobenzofuranone nucleus. Moreover, this aromatic ring is oxygenated at the $\mathrm{C}-2^{\prime} / \mathrm{C}-6^{\prime}$ positions and exhibits an alkyl group (isopropyl) attached to $\mathrm{C}-4^{\prime}$ (see Scheme 1 for numbering). Thus, these structural features seem to be important in terms of the antileishmanial activities of the investigated compounds. Notably, a previous investigation of the cytotoxicities of compounds 2-11 against the K562 and U937 cancer cell lines [22] revealed that the most active compounds exhibited structural features similar to these aforementioned features. Indeed, isobenzofuranone 7 was one of the most active compounds against $\mathrm{K} 562$ exhibiting an $\mathrm{LC}_{50}$ of $2.79 \mu \mathrm{M}$ and was even more potent than the anticancer agent etoposide (VP-16), which was used as a positive control. Due to the superior antileishmanial activities of compounds 7 and 8 after $24 \mathrm{~h}$ (Figure 2A), these compounds were selected for further evaluation.

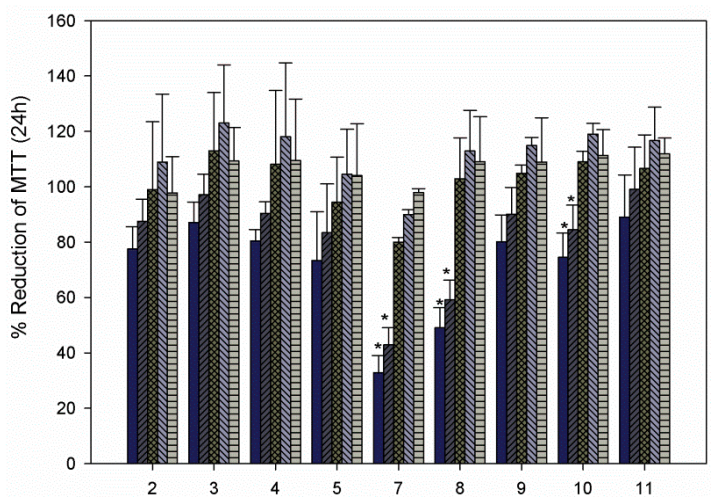

(A)

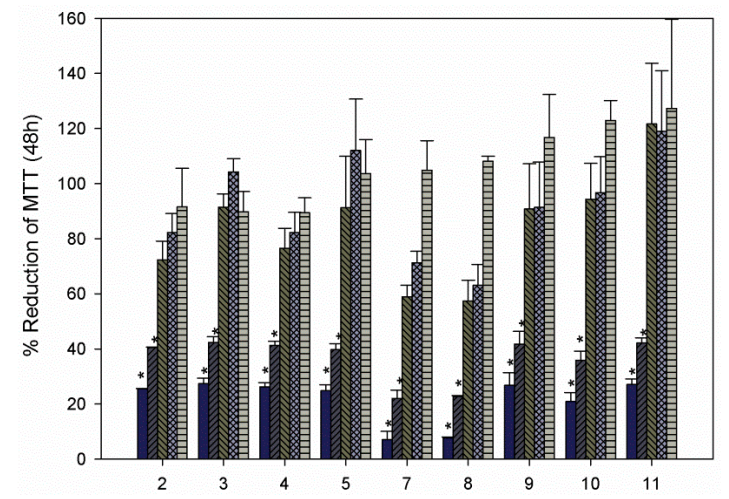

(B)

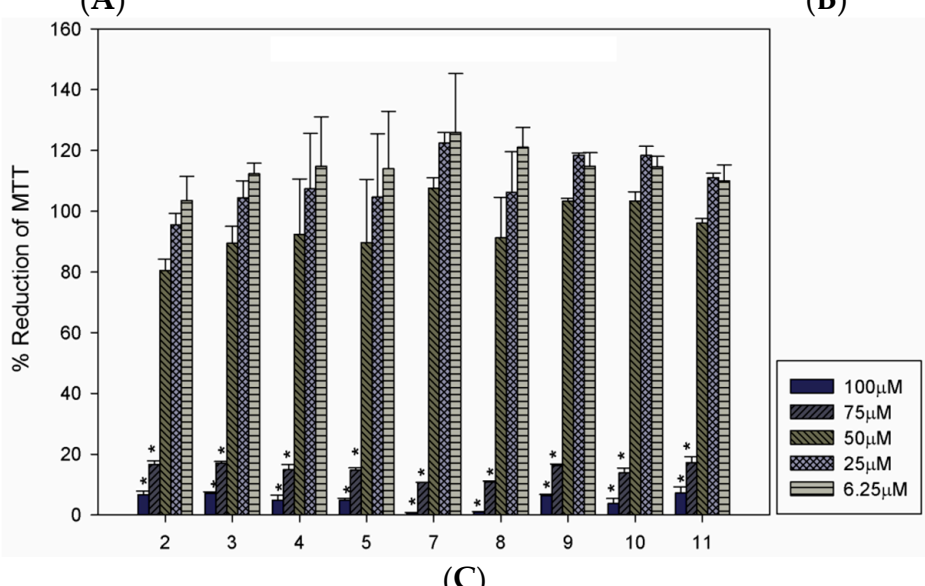

(C)

Figure 2. Leishmanicidal activities of isobenzofuranones $\mathbf{2}-\mathbf{5}$ and $\mathbf{7 - 1 1}$ against promastigotes. MTT viability assays were used to evaluate the promastigotes of L. infantum after 24 (A); 48 (B); and $72 \mathrm{~h}$ (C) of treatment. The results are presented as the averages and the SDs of three independent experiments that were performed in triplicate. The * indicates significant differences compared with the control at $p<0.05$. 
Table 1. Antileishmanial efficacies of isobenzofuranones against promastigotes.

\begin{tabular}{cccc}
\hline \multirow{2}{*}{ Compound } & \multicolumn{3}{c}{ LC $_{\mathbf{5 0}}(\boldsymbol{\mu M})^{\mathbf{a}}$} \\
\cline { 2 - 4 } & $\mathbf{2 4} \mathbf{h}$ & $\mathbf{4 8} \mathbf{h}$ & $\mathbf{7 2} \mathbf{~}$ \\
\hline $\mathbf{2}$ & 74.54 & 65.55 & 58.96 \\
$\mathbf{3}$ & $>100$ & 65.73 & 59.08 \\
$\mathbf{4}$ & $>100$ & 65.69 & 59.20 \\
$\mathbf{5}$ & $>100$ & 61.69 & 58.96 \\
$\mathbf{7}$ & 60.48 & 62.72 & 59.75 \\
$\mathbf{8}$ & 65.93 & 63.90 & 58.46 \\
$\mathbf{9}$ & 75.01 & 54.78 & 60.51 \\
$\mathbf{1 0}$ & 74.27 & 61.84 & 60.53 \\
$\mathbf{1 1}$ & $>100$ & 30.79 & 60.17 \\
\hline
\end{tabular}

a The $\mathrm{LC}_{50}$ values were calculated at 24,48 and $72 \mathrm{~h}$ of treatment. The data are representative of three independent experiments.

The second investigation examined the toxicities isobenzofuranones $\mathbf{7}$ and $\mathbf{8}$ against macrophages, which are the main cells that are infected by Leishmania parasites in leishmaniasis diseases. We observed low levels of toxicity at high isobenzofuranones concentrations $(100 \mu \mathrm{M})$ and selected a lower dose to perform the infection assays $(75 \mu \mathrm{M})$. Both compounds decreased the levels of infection and reduced the numbers of intracellular parasites per infected cell. Together, these results suggest that these compounds may affect both infection capability and intracellular proliferation. In an investigation of the possible mechanism of action of C-3 functionalized isobenzofuranones against the HL-60 cancer cell line, Logrado and collaborators found that the active compounds exerted their effect on HL-60 cells via direct DNA damage or the generation of free radicals [21]. Although the mechanisms of action of the most active compounds were not investigated here, it is possible that the antileishmanial activities that were observed for compounds $\mathbf{7}$ and $\mathbf{8}$ are also related to these mechanisms. Conceivably, due to the intense replication of this parasite during acute infection, it could be strongly affected by DNA damage or free radicals. Indeed, reports in the literature have indicated that anti-cancer drugs that affect cellular proliferation can be used as anti-microbial agents because both cell types share common behaviors concerning their high proliferative capabilities [27-29]. Indeed, a recent work evidenced the antileishmanial actions of other two isobenzofuranone derivatives and indicated that these actions were due to the induction of reactive oxygen species (ROS)-mediated apoptosis-like cell death and the inhibition of topoisomerases [30].

To assess whether the compounds tested on the parasites affected cell viability, RAW macrophages were maintained for 24, 48 and $72 \mathrm{~h}$ in the presence of compounds 7 and 8 at concentrations that ranged from 6.25 to $100 \mu \mathrm{M}$. There were no significant differences in cellular viability after $24 \mathrm{~h}$ with the tested concentrations of compound 7 (Figure 3A). However, the viabilities of the macrophages were significantly affected after 48 and $72 \mathrm{~h}$ of treatment at $100 \mu \mathrm{M}$ (Figure 3B,C). Regarding compound 8 , the $100 \mu \mathrm{M}$ concentration affected the viability after $24 \mathrm{~h}$ (Figure 3A). However, concentrations of $75 \mu \mathrm{M}$ and lower did not seem to affect the macrophages (Figure 3). Based on these results, the $75 \mu \mathrm{M}$ concentration was selected for the infection assays.

Next, macrophages were infected with $L$. (L.) infantum chagasi and subsequently treated with isobenzofuranones 7 and $\mathbf{8}$ at $75 \mu \mathrm{M}$ for $24 \mathrm{~h}$. Regarding compound 7 , a reduction of the number of infected cells by approx. $65 \%$ was observed (Figure $4 \mathrm{~A}$ ). This effect was even more pronounced for compound 8 , which reduced the number of infected cells by $76 \%$ (Figure $4 \mathrm{~B}$ ). 


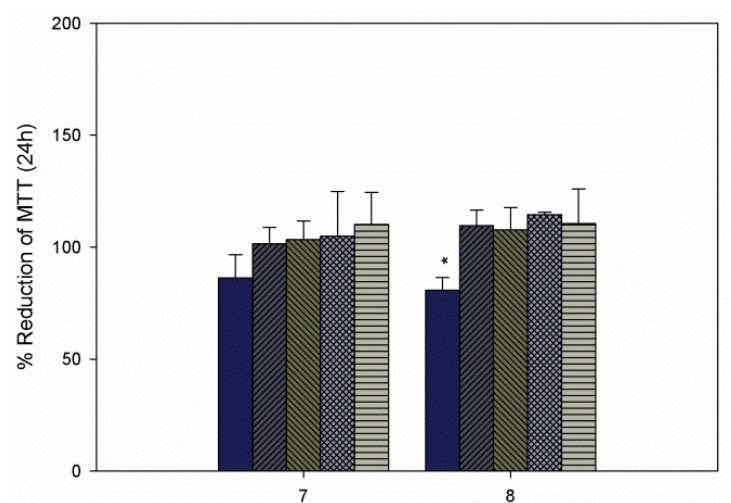

(A)

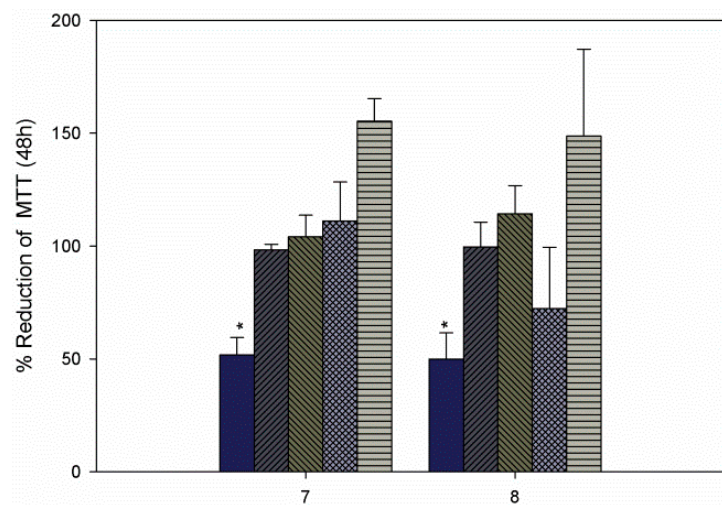

(B)

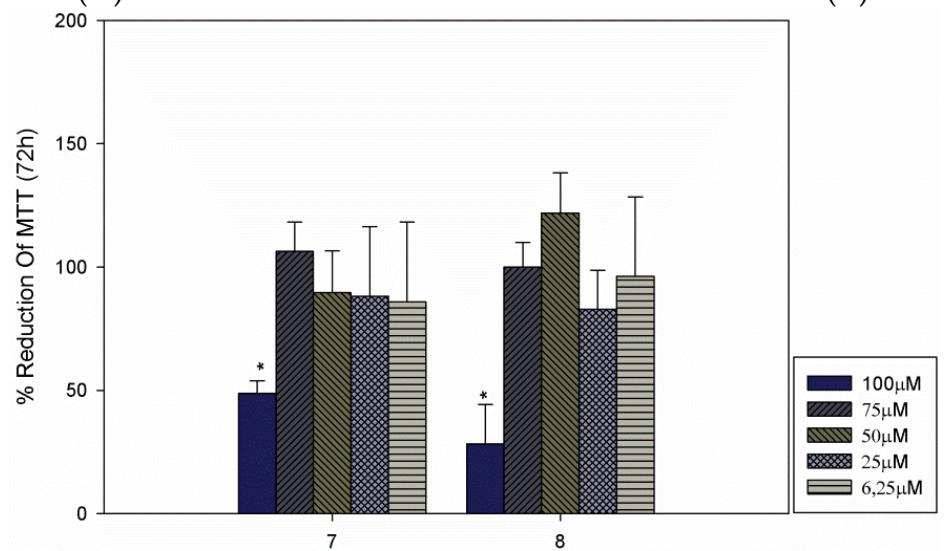

(C)

Figure 3. Toxicities of isobenzofuranones $\mathbf{7}$ and $\mathbf{8}$ to RAW macrophages. MTT viability assays were performed after $24 \mathrm{~h}(\mathbf{A}) ; 48 \mathrm{~h}(\mathbf{B})$ and $72 \mathrm{~h}(\mathbf{C})$ of treatment. The results are presented as the averages and the SDs of three independent experiments that were performed in triplicate. The * indicates significant differences compared with the control at $p<0.05$.
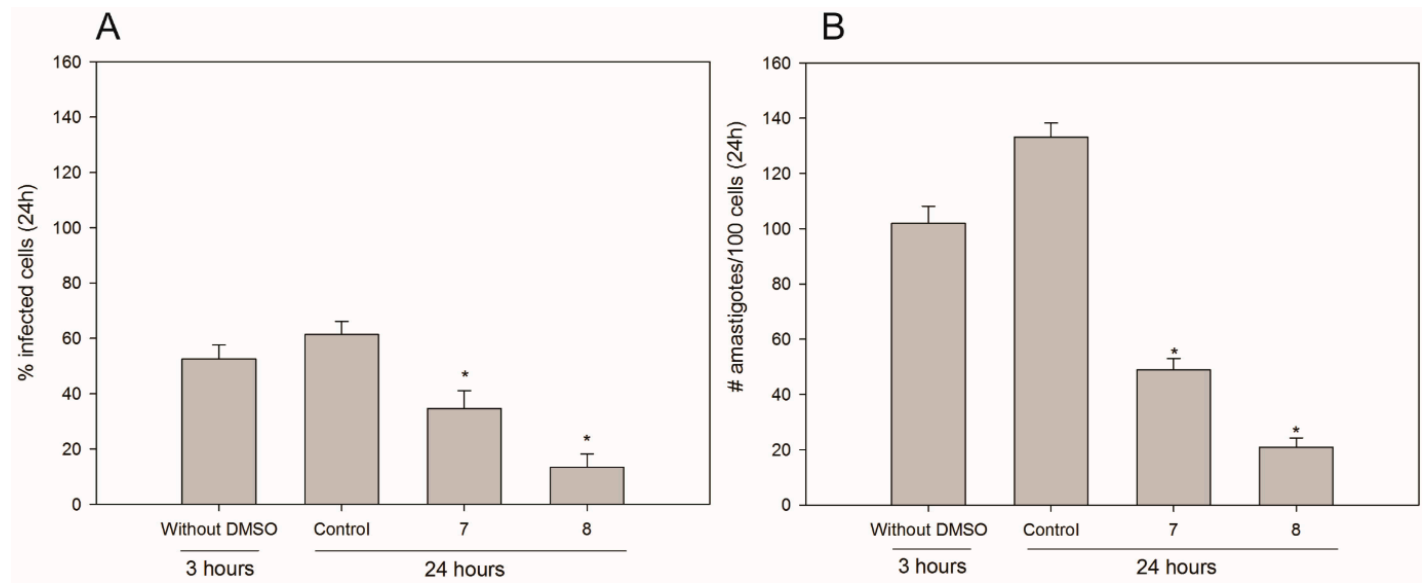

Figure 4. Leishmanicidal activities of compounds 7 and 8 in infected RAW macrophages. The percentages of infected macrophages (A); and the numbers of intracellular amastigotes per 100 cells (B) were assessed. The first column (without DMSO) is the control after $3 \mathrm{~h}$ of infection and before the addition of $1 \%$ DMSO. The second column is the sample assay after $24 \mathrm{~h}$ of infection in the presence of DMSO. The last two columns are the samples with isobenzofuranones $\mathbf{7}$ and $\mathbf{8}$ at the concentration of $75 \mu \mathrm{M}$ in $1 \%$ DMSO. The data are presented the averages and the SDs of three independent experiments that were performed in triplicate. The * indicates significant differences compared with the control at $p<0.05$. 
Importantly, although compound 7 did not affect the viability of the macrophages as assessed with the MTT method, we observed visible changes in their morphologies (Figure 5B). This phenotype was not observed for compound $\mathbf{8}$, which did not cause any visible changes in the overall cell morphology (Figure 5C). These findings suggest that the compounds 7 and 8 differ in their mechanism of action, which should be better investigated in future studies.

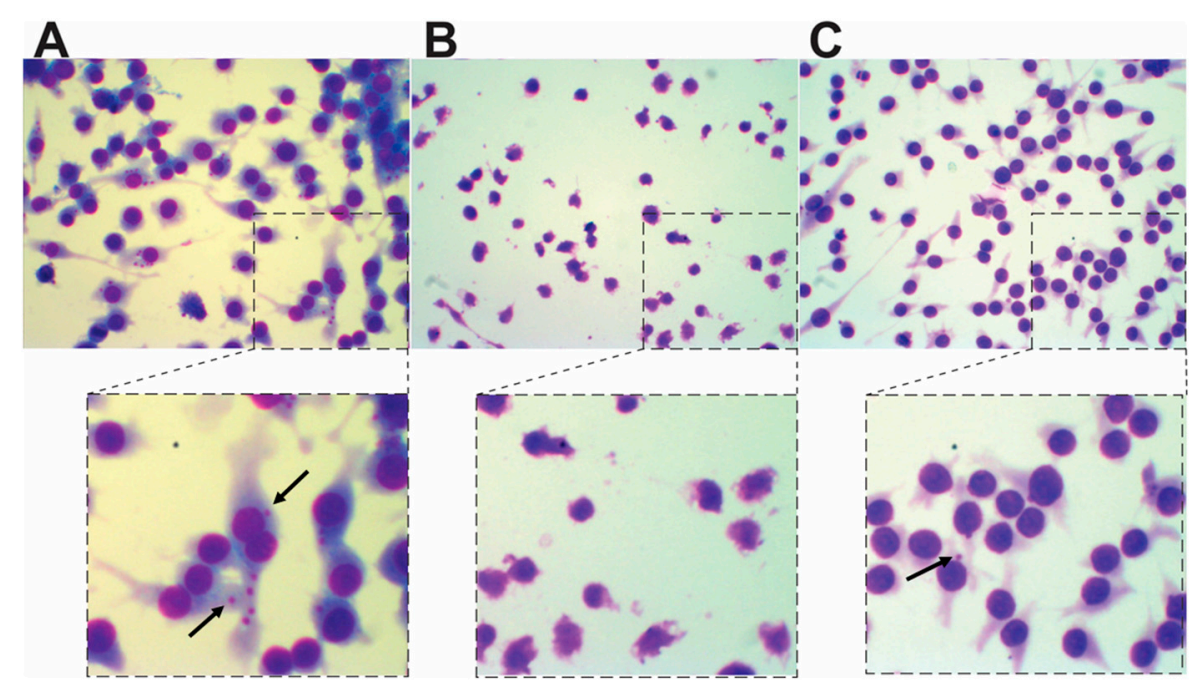

Figure 5. Representative micrographs showing RAW macrophages infected with $L$. (L) infantum chagasi that were or were not treated compounds 7 or 8 . The infected macrophages were treated for $24 \mathrm{~h}$ with $1 \%$ DMSO (control) (A); $75 \mu \mathrm{M}$ of compound 7 (B); or $75 \mu \mathrm{M}$ of compound 8 (C). The pictures are representative of all of the experiments, which were conducted as independent triplicates. The upper pictures are magnified at 100x, and the lower panels are zoomed in images of the selected parts of the upper pictures. The black arrows indicate intracellular amastigotes.

\section{Experimental Section}

\subsection{Syntheses}

The syntheses of the isobenzofuranones were performed as previously reported [22]). Compounds 2-11 were prepared using condensation, aromatization and acetylation reactions (Scheme 1). Briefly, DBU-mediated condensation reactions between commercially available phthalaldehydic acid (1) and cyclic and acyclic 1,3-diketones produced compounds 2, 5, 6, 9, 10 and 11. The aromatization of phthalides 2 and 6 produced the aromatic derivatives 3 and 7 . The acetylation of compounds 3 and 7 led to the preparation of substances 4 and 8 . The structural characterizations of these compounds have been described previously [19]. Stock solutions of the compounds were prepared by dissolving them in $100 \%$ DMSO. The solutions were maintained at $4{ }^{\circ} \mathrm{C}$ until use. Due to the limited amount of compound 6, this phtalide was not evaluated.

\subsection{Obtaining of Promastigotes Parasites and Leishmanicidal Activity Evaluation}

L. (L.) infantum chagasi strain M2682 was grown in Grace's insect medium supplemented with $10 \%$ heat-inactivated fetal calf serum, $2 \mathrm{mM}$ L-glutamine and $100 \mathrm{U} / \mathrm{mL}$ penicillin $\mathrm{G}$ potassium at $\mathrm{pH} 6.5$ and $26^{\circ} \mathrm{C}$. On the third day (exponential phase), the promastigote parasites were washed with culture medium, plated at $1 \times 10^{6}$ Leishmania/mL without (control) or with $100 \mu \mathrm{M}$ of isobenzofuran-1(3H)-ones 2-5 and 7-11, and incubated at $26{ }^{\circ} \mathrm{C}$ for 24,48 and $72 \mathrm{~h}$. After incubation, $1 \mathrm{mM}$ of 3-(4,5-dimethylthiazol-2-yl)-2,5-diphenyltetrazolium bromide (MTT) was added and followed by an incubation for $2 \mathrm{~h}$ at $26^{\circ} \mathrm{C}$. Subsequently, the parasites were centrifuged at $1400 \times g$, the supernatants were discarded, and $100 \mu \mathrm{L}$ of dimethylsulfoxide (DMSO) was added to the pellet, which 
was subsequently stirred for $15 \mathrm{~min}$ and reading at $595 \mathrm{~nm}$. The calculations of the viable parasites were performed using the following equation:

$$
\frac{\text { absorbance of the test }- \text { absorbance of the plate }}{\text { absorbance of the control-absorbance of the plate }} \times 100
$$

\subsection{Cultivation of Macrophages and Cytotoxicity Evaluation}

The mouse leukemic macrophage cell line RAW (RAW) were grown in Roswell Park Memorial Institute Media (RPMI) supplemented with $10 \%(v / v)$ heat-inactivated fetal calf serum (LGC Bio ${ }^{\circledR}$, Petaluma, CA, USA), $100 \mathrm{U} / \mathrm{mL}$ penicillin $\left(\right.$ Sigma ${ }^{\circledR}$, St. Louis, MO, USA), and $100 \mu \mathrm{g} / \mathrm{mL}$ streptomycin $\left(\right.$ Sigma ${ }^{\circledR}$ ) in flasks of 75 or 150 or $300 \mathrm{~cm}^{3}$, which were maintained at $37{ }^{\circ} \mathrm{C}$ in an atmosphere with $95 \%$ humidity and $5 \% \mathrm{CO}_{2}$. Thereafter, the macrophages were transferred to 96 -well plates at a concentration of $1 \times 10^{6}$ macrophages $/ \mathrm{mL}$. The compounds were added to the culture medium at different concentrations and incubated at $37^{\circ} \mathrm{C}\left(5 \% \mathrm{CO}_{2}\right)$ for 24,48 and $72 \mathrm{~h}$. After incubation, $1 \mathrm{mM}$ of MTT was added in each well, and the cultures were returned to the incubator for $2 \mathrm{~h}$. Next, the culture medium was discarded, and $100 \mu \mathrm{L}$ DMSO was added, and the wells were stirred for $15 \mathrm{~min}$ and subsequently read at $595 \mathrm{~nm}$. The calculations of the percentages of viable cells were performed as described in the previous section.

\subsection{Infection Assays}

The macrophages were left to adhere in the 24-well plate (which included a sterile coverslip for each well) for 90-120 min at a concentration of $1 \times 10^{6} / \mathrm{mL}$. The cells were washed twice with PBS to remove the non-adhered cells. For infection, $3-5 \times 10^{6}$ parasites $/ \mathrm{mL}$ suspended in RPMI with $10 \%$ fetal calf serum were added to macrophage cells, which were then left to be infected for $3 \mathrm{~h}$ (5 Leishmania per macrophage). Next, the wells were washed twice with PBS to remove the parasites that did not infect macrophages. Subsequently, RPMI with 10\% fetal calf serum containing the compounds at the different concentrations specified in the figures was added. All samples, including the controls, contained 1\% DMSO (final DMSO concentration in the working solution). The cultures were incubated for 24 or $48 \mathrm{~h}$ in the same conditions described above. After incubation, the cells were fixed on coverslips with methanol and stained with Fast Panoptic FAST kit (Panreac AppliChem, Darmstadt, Germany) according to the manufacturer's recommendations. All assays were performed in triplicate, and the stained coverslips were analyzed by light microscopy. We evaluated the numbers of infected macrophages and the numbers of intracellular amastigotes per 100 macrophages.

\section{Conclusions}

The potential of diverse C-3 substituted isobenzofuran-1(3H)-ones as antileishmanial agents against Leishmania (L.) infantum chagasi (syn. Leishmania infantum) was evaluated. The efficacies of the compounds against promastigote viability were dependent on the type of substituent attached to the C-3 position. Among the compounds evaluated, the isobenzofuranones 7 and 8 were found to be capable of significantly reducing the percentage of infected macrophages and the number of intracellular amastigotes per infected macrophage. Based on the results obtained, these isobenzofuranones may represent a novel scaffold that can be exploited to develop of new drugs for the treatment of leishmaniasis.

Acknowledgments: This work was supported by the Conselho Nacional de Desenvolvimento Científico e Tecnológico (CNPq) fellowship 552459/2011-9 to JLRF and MRA, the MCT/CAPES/FAPEMIG fellowship CNPq 550514/2011-2 and Fundação de Amparo à Pesquisa do Estado de Minas Gerais (FAPEMIG) CBB-APQ-01354-13; CEX-BPD-00174-13; CEX APQ 01287/14.

Author Contributions: W.L.P. and A.M.S. synthesized the isobenzofuranones. R.S.V., C.M.M., R.S.G., R.C.F., A.S.J., G.C.B., M.R.A., L.C.C.A. designed and conducted the biological assays. R.R.T. and J.L.R.F. wrote the paper. All of the authors contributed in the revision of manuscript. 
Conflicts of Interest: The authors declare no conflict of interest.

\section{References}

1. WHO. Leishmaniasis; Fact Sheet No. 375; WHO: Geneva, Switzerland, 2015. Available online: http://www.who.int/mediacentre/factsheets/fs375/en/ (accessed on 30 October 2015).

2. WHO. Control of leishmaniases. Technical Report Series, No. 949; WHO: Geneva, Switzerland, 2010.

3. Shawn, J. Further thoughts on the use of the name Leishmania (Leishmania) infantum chagasi for the aetiological agent of American visceral leishmaniasis. Mem. Inst. Oswaldo Cruz 2006, 101, 577-579. [CrossRef]

4. Alvonar, J.; Vélez, I.D.; Bern, C.; Herrero, M.; Desjeux, P.; Cano, J.; Jannin, J.; den Boer, M. Leishmaniasis worldwide and global estimates of its incidence. PLoS ONE 2012, 7, e35671. [CrossRef] [PubMed]

5. Sundar, S.; Chakravarty, J. Investigational drugs for visceral leishmaniasis. Expert Opin. Investig. Drugs 2015, 24, 43-59. [CrossRef] [PubMed]

6. De Souza, R.F.; dos Santos, Y.L.; de Souza Vasconcellos, R.; Borges-Pereira, L.; Caldas, I.S.; de Almeida, M.R.; Bahia, M.T.; Fietto, J.L. Recombinant Leishmania (Leishmania) infantum Ecto-Nucleoside Triphosphate Diphosphohydrolase NTPDase-2 as a new antigen in canine visceral leishmaniasis diagnosis. Acta Trop. 2013, 125, 60-66. [CrossRef] [PubMed]

7. Gramiccia, M.; Gradoni, L. The current status of zoonotic leishmaniases and approaches to disease control. Int. J. Parasitol. 2005, 35, 1169-1180. [CrossRef] [PubMed]

8. Frezard, F.; Demicheli, C.; Ribeiro, R.R. Pentavalent antimonials: New perspectives for old drugs. Molecules 2009, 14, 2317-2336. [CrossRef] [PubMed]

9. Garcia Bustos, M.F.; Barrio, A.; Gonzalez Prieto, G.; de Molina Raspi, E.; Cimino, R.; Cardozo, R.M.; Parada, L.A.; Yeo, M.; Soto, J.; Uncos, D.A.; et al. In Vivo Antileishmanial Efficacy of Miltefosine against Leishmania (Leishmania) Amazonensis. J. Parasitol. 2014, 100, 840-847. [CrossRef] [PubMed]

10. Croft, S.L.; Sundar, S.; Fairlamb, A.H. Drug resistance in leishmaniasis. Clin. Microbiol. Rev. 2006, 19, 111-126. [CrossRef] [PubMed]

11. Croft, S.L.; Coombs, G.H. Leishmaniasis-Current chemoteraphy and recent advances in the search for novel drugs. Trends Parasitol. 2003, 19, 502-508. [CrossRef] [PubMed]

12. Ouellette, M.; Drummelsmith, J.; Papadopoulou, B. Leishmaniasis: Drugs in the clinic, resistance and new developments. Drug Resist. Update 2004, 7, 257-266. [CrossRef] [PubMed]

13. Monzote, L. Current treatment of leishmaniasis: A review. Open Antimicrob. Agents J. 2009, 1, 9-19.

14. Monge-Maillo, B.; Lopez-Velez, R. Therapeutic options for visceral leishmaniasis. Drugs 2013, 73, $1863-1888$. [CrossRef] [PubMed]

15. Lin, G.; Chan, S.-K.; Chung, H.-S.; Li, S.-L. Chemistry and biological activities of naturally occurring phthalides. In Studies in Natural Products Chemistry; Atta-ur-Rahman, Ed.; Elsevier: Amsterdam, The Nederland, 2005; pp. 611-669.

16. Zhang, W.; Xu, L.; Yang, L.; Huang, Y.; Li, S.; Shen, Y. Phomopsidone A, a novel depsidone metabolite from the mangrove endophytic fungus Phomopsis sp. A123. Fitoterapia 2014, 96, 146-151. [CrossRef] [PubMed]

17. Ma, F.; Gao, Y.; Qiao, H.; Hu, X.; Chang, J. Antiplatelet activity of 3-butyl-6-bromo-1(3H)-isobenzofuranone on rat platelet aggregation. J. Thromb. Thrombolysis 2012, 33, 64-73. [CrossRef] [PubMed]

18. Johnston, G.A. Advantages of an antagonist: Bicuculline and other GABA antagonists. Br. J. Pharmacol. 2013, 169, 328-336. [CrossRef] [PubMed]

19. Zhao, N.; Ji, M.-X.; Xu, L.; Ji, B.-S. 3-butyl-6-fluoro-1(3H)-isobenzofuranone (6-F-NBP), a derivative of $d l$-n-butylphthalide, inhibits glutamate-induced cytotoxicity in PC12 cells. Drug Dev. Res. 2012, 73, 11-17. [CrossRef]

20. Arnone, A.; Assante, G.; Nasini, G.; Strada, S.; Vercesi, A. Cryphonectric acid and other minor metabolites from a hypovirulent strain of Cryphonectria parasitica. J. Nat. Prod. 2002, 65, 48-50. [CrossRef] [PubMed]

21. Logrado, L.P.; Santos, C.O.; Romeiro, L.A.; Costa, A.M.; Ferreira, J.R.; Cavalcanti, B.C.; de Manoel Moraes, O.; Costa-Lotufo, L.V.; Pessoa, C.; dos Santos, M.L. Synthesis and cytotoxicity screening of substituted isobenzofuranones designed from anacardic acids. Eur. J. Med. Chem. 2010, 45, 3480-3489. [CrossRef] [PubMed] 
22. Teixeira, R.R.; Bressan, G.C.; Pereira, W.L.; Ferreira, J.G.; de Oliveira, F.M.; Thomaz, D.C. Synthesis and antiproliferative activity of C-3 functionalized isobenzofuran-1(3H)-ones. Molecules 2013, 18, 1881-1896. [CrossRef] [PubMed]

23. Rahman, M.M.; Gray, A.I. A benzoisofuranone derivative and carbazole alkaloids from Murraya koenigii and their antimicrobial activity. Phytochemistry 2005, 66, 1601-1606. [CrossRef] [PubMed]

24. Teixeira, R.R.; Pereira, J.L.; da Silva, S.F.; Guilardi, S.; Paixão, D.A.; Anconi, C.P.A.; de Almeida, W.B.; Ellena, J.; Forlani, G. Synthesis, characterization and phytotoxic activity of hydroxylated isobenzofuran-1(3H)-ones. J. Mol. Struct. 2014, 1061, 61-68. [CrossRef]

25. Kwan, C.N.; Medoff, G.; Kobayashi, G.S.; Schlessinger, D.; Raskas, H.J. Potentiation of the antifungal effects of antibiotics by amphotericin B. Antimicrob. Agents Chemother. 1972, 2, 61-65. [CrossRef] [PubMed]

26. Strobel, G.; Ford, E.; Worapong, J.; Harper, J.K.; Arif, A.M.; Grant, D.M.; Fung, P.C.W.; Chaud, R.M.W. Isopestacin, an isobenzofuranone from Pestalotiopsis microspora, possessing antifungal and antioxidant activities. Phytochemistry 2002, 60, 179-183. [CrossRef]

27. Dorosti, Z.; Yousefi, M.; Sharafi, S.M.; Darani, H.Y. Mutual action of anticancer and antiparasitic drugs: Are there any shared targets? Future Oncol. 2014, 10, 2529-2539. [CrossRef] [PubMed]

28. Vlahopoulos, S.; Critselis, E.; Voutsas, I.F.; Perez, S.A.; Moschovi, M.; Baxevanis, C.N.; Chrousos, G.P. New use for old drugs? Prospective targets of chloroquines in cancer therapy. Curr. Drug Targets 2014, 15, 843-885. [CrossRef] [PubMed]

29. Wang, B.; Yu, W.; Guo, J.; Jiang, X.; Lu, W.; Liu, M.; Pang, X. The antiparasitic drug, potassium antimony tartrate, inhibits tumor angiogenesis and tumor growth in nonsmall-cell lung cancer. J. Pharmacol. Exp. Ther. 2015, 352, 129-138. [CrossRef] [PubMed]

30. Mishra, A.; Vinayagam, J.; Saha, S.; Chowdhury, S.; Roychowdhury, S.; Jaisankar, P.; Majumder, H.K. Isobenzofuranone derivatives exhibit antileishmanial effect by inhibiting type II DNA topoisomerase and inducing host response. Pharmacol. Res. Perspect. 2014, 2, e00070. [CrossRef] [PubMed]

Sample Availability: Samples of the compounds 2-11 are available from the authors.

(C) 2015 by the authors; licensee MDPI, Basel, Switzerland. This article is an open access article distributed under the terms and conditions of the Creative Commons by Attribution (CC-BY) license (http:/ / creativecommons.org/licenses/by/4.0/). 